\title{
Características morfogênicas e estruturais de perfilhos de capim-braquiária em locais do pasto com alturas variáveis
}

\author{
Manoel Eduardo Rozalino Santos ${ }^{1}$, Dilermando Miranda da Fonseca ${ }^{2}$, Thiago Gomes dos \\ Santos Braz ${ }^{1}$, Simone Pedro da Silva ${ }^{3}$, Virgilio Mesquita Gomes ${ }^{1}$, Guilherme Portes Silva ${ }^{4}$ \\ 1 Doutorando do Departamento de Zootecnia - Universidade Federal de Viçosa. \\ 2 Departamento de Zootecnia - Universidade Federal de Viçosa. \\ ${ }^{3}$ Mestranda do Departamento de Zootecnia - Universidade Federal de Viçosa. \\ ${ }^{4}$ Graduando do curso de Agronomia - Universidade Federal de Viçosa.
}

RESUMO - O experimento foi conduzido com o objetivo de avaliar a influência das variações naturais da altura da planta no mesmo pasto sobre as características morfogênicas e estruturais da Brachiaria decumbens cv. Basilisk manejada sob lotação contínua com bovinos. Foram avaliadas quatro alturas de plantas (10, 20, 30 e $40 \mathrm{~cm}$ ) no mesmo pasto manejado com altura média de $25 \mathrm{~cm}$. Adotou-se o delineamento em blocos ao acaso com duas repetições. A taxa de aparecimento foliar do capimbraquiária foi influenciada linear e negativamente pelas alturas das plantas no mesmo pasto. Os perfilhos presentes nos locais com maior altura apresentaram maior filocrono (9,3 dias). A maior altura das plantas no mesmo pasto promoveu maiores taxas de senescência foliar e de alongamento de pseudocolmo no perfilho. A duração de vida da folha (37,8 dias) e a taxa de alongamento foliar (1,3 cm/perfilho.dia) não foram influenciadas pela altura da planta. Os números de folhas vivas $(4,36)$ e mortas $(2,15)$ também não foram modificados pela altura da planta. Já a maior altura das plantas resultou em aumento linear de 69\% no número de folhas com desfolhação. Os comprimentos do pseudocolmo e da lâmina foliar responderam linear e positivamente ao aumento na altura da planta no mesmo pasto. A variação natural na altura da planta no mesmo pasto altera as características morfogênicas e estruturais do capim-braquiária. Existe variabilidade espacial da vegetação em pastos de Brachiaria decumbens cv. Basilisk manejados sob lotação contínua com bovinos.

Palavras-chave: Brachiaria decumbens, estrutura horizontal do pasto, lâmina foliar, morfogênese, pastejo, pseudocolmo

\section{Morphogenic and structural characteristics of tillers on areas with signalgrass pasture varying on height}

\begin{abstract}
The objective of this experiment was to evaluate the influence of natural variation of heights of plants on the same pasture on the morphogenic and structural characteristics of Brachiaria decumbens cv. Basilisk managed under continuous stocking with cattle. Four plant heights $(10,20,30$ and $40 \mathrm{~cm})$ were evaluated on the same pasture managed at an average height of $25 \mathrm{~cm}$. It was used a randomized block design with two replications. Leaf appearance rate of signalgrass was linearly and negatively influenced by heights of the plants on the same pasture. The tillers on the same sites with the highest heights showed greater phyllochron (9.3 days). The higher plant heights on the same pasture promoted both higher leaf senescence and pseudoculm elongation rates for the tillers. Leaf lifespan (37.8 days) and leaf elongation rate (1.3 cm/tillers.day) were not influenced by the plant height. The number of green (4.36) and dead (2.15) leaves was not changed by the plants height either. However, the higher height of plants resulted in a linear increase of $69 \%$ on the number of leaves showing defoliation. Pseudoculm and leaf blade lengths responded linearly and positively to the increase in the plants height on the same pasture. The natural height variance of plants found on the same pasture changes the morphogenetic and structural characteristics of signalgrass. There is spatial variability of the vegetation on Brachiaria decumbens cv. Basilisk pastures managed under continuous stocking with bovine.
\end{abstract}

Key Words: Brachiaria decumbens, grazing, horizontal sward of pasture, leaf blade, morphogenesis, pseudoculm

\section{Introdução}

Um dos principais objetivos com o manejo do pastejo é fazer com que a maior parte da forragem consumida pelo animal seja composta por lâminas foliares. Contudo, são diversos os fatores que influenciam os processos que resultam na disponibilização dessa lâmina foliar ao animal. Nesse sentido, fatores como luz, temperatura, água, nutrientes e o próprio manejo afetam o processo de fotossíntese e a dinâmica de crescimento e desenvolvimento 
de lâminas foliares no pasto. De fato, a compreensão do desenvolvimento dos órgãos das forrageiras consiste no primeiro passo para a definição de estratégias racionais de manejo de pastagens (Gomide et al., 2006).

Parcela significativa dos sistemas de produção pecuários no Brasil é baseada no uso de pastagens de Brachiaria decumbens sob lotação contínua. Entre os possíveis critérios para nortear o manejo do pastejo em condições de lotação contínua, destaca-se o uso de valores de altura média do pasto, bem como o uso da taxa de lotação variável (Da Silva \& Nascimento Júnior, 2007). Dessa forma, pode-se admitir como recomendável a faixa de altura entre 20 a $30 \mathrm{~cm}$ para o pasto de $B$. decumbens manejado em lotação contínua (Gomide, 2006; Santos, 2009).

Todavia, a manutenção do pasto na altura média prédefinida nem sempre é facilitada, porque os animais apresentam preferência de pastejo por determinados locais do mesmo pasto em detrimento aos outros (Carvalho et al., 2001). Adicionalmente, a existência de gradiente nos fatores interferentes no crescimento da forrageira na pastagem, tais como variações locais em fertilidade e umidade do solo, também determinam a variabilidade espacial da vegetação no mesmo pasto.

Essa heterogeneidade espacial das plantas no mesmo pasto é dinâmica (Santos, 2009) e determina a sua estrutura horizontal, que é importante em todas as escalas da interação planta-animal (Carvalho et al., 2001), mas tem sido pouco avaliada (Schwartz, 2003; Braga et al., 2007; Santos, 2009) nos experimentos com animais em pastejo.

A ocorrência de locais com alturas diferentes dentro do mesmo pasto caracteriza sua estrutura horizontal e confere condições de microclima diferenciadas no plano horizontal do pasto, que podem modificar a morfogênese e a estrutura dos perfilhos individuais e, por seu turno, alterar o índice de área foliar e o acúmulo de forragem do pasto.

Assim, objetivou-se com este trabalho avaliar a influência das variações naturais da altura da planta no mesmo pasto sobre as características morfogênicas e estruturais da Brachiaria decumbens cv. Basilisk manejada sob lotação contínua com bovinos.

\section{Material e Métodos}

Este trabalho foi conduzido de novembro de 2007 a maio de 2008 numa área de pastagem de Brachiaria decumbens cv. Basilisk(Stapf.) (capim-braquiária) estabelecida em 1997, pertencente ao Setor de Forragicultura do Departamento de Zootecnia da Universidade Federal de Viçosa. A área experimental foi constituída de dois piquetes (unidades experimentais) de aproximadamente 0,30 ha cada, além de uma área reserva. O solo da área experimental é latossolo vermelho-amarelo de textura argilosa. A análise química do solo, realizada no início do período experimental, na camada 0-20 cm, apresentou os seguintes resultados: $\mathrm{pH}$ em $\mathrm{H}_{2} \mathrm{O}$ : 5,1; P: 2,9 (Mehlich-1) e K: 85 mg/ $\mathrm{dm}^{3} ; \mathrm{Ca}^{2+}: 2,05 ; \mathrm{Mg}^{2+}$ : $0,45 \mathrm{e} \mathrm{Al}^{3+}: 0,19 \mathrm{cmol}_{\mathrm{C}} / \mathrm{dm}^{3}(\mathrm{KCl} 1 \mathrm{~mol} / \mathrm{L})$. Durante o período de avaliação os dados climáticos foram registrados em estação meteorológica distante da área experimental aproximadamente $500 \mathrm{~m}$ (Tabela 1).

A adubação fosfatada foi efetuada no dia 16 de janeiro de 2008, com a aplicação de $70 \mathrm{~kg} /$ ha de $\mathrm{P}_{2} \mathrm{O}_{5}$, na forma de superfosfato simples, em toda área experimental. A adubação nitrogenada, na forma de uréia, foi realizada em três aplicações de $50 \mathrm{~kg} / \mathrm{ha}$ de $\mathrm{N}$ ao final da tarde de cada data de aplicação (16/1/2008, 26/2/2008 e 07/4/2008).

Desde novembro de 2007, os piquetes foram manejados sob lotação contínua com taxa de lotação variável a fim de manter a altura do pasto em cerca de $25 \mathrm{~cm}$. Para isso, a altura do pasto foi monitorada duas vezes por semana e foram utilizados bovinos machos, em recria, com peso médio de $200 \mathrm{~kg}$.

Foram avaliadas quatro alturas de plantas (10, 20, 30 e $40 \mathrm{~cm}$ ) no mesmo pasto manejado com altura média de $25 \mathrm{~cm}$, o que foi possível devido à natural variabilidade espacial da vegetação. Adotou-se o delineamento em blocos ao acaso com duas repetições (piquetes).

No início de janeiro de 2008, o pasto de capim-braquiária foi infestado pela lagarta Mocis latipes, o que impediu a realização e continuidade das avaliações de campo, que haviam iniciado em meados de dezembro de 2007. Com a infestação da lagarta, retiraram-se os animais dos piquetes

Tabela 1 - Médias mensais da temperatura média diária, insolação, precipitação pluvial total mensal e evaporação total mensal durante os períodos de novembro de 2007 a maio de 2008

\begin{tabular}{lcccc}
\hline Mês & Temperatura média do ar $\left({ }^{\circ} \mathrm{C}\right)$ & Insolação (horas/dia) & Precipitação pluvial $(\mathrm{mm})$ & Evaporação $(\mathrm{mm})$ \\
\hline Novembro de 2007 & 21,9 & 4,9 & 52,6 & 175,7 \\
Dezembro de 2007 & 22,9 & 10,7 & 219,5 & 87,7 \\
Janeiro de 2008 & 21,6 & 8,2 & 112,7 & 42,4 \\
Fevereiro de 2008 & 22,7 & 8,5 & 239,2 & 634,6 \\
Março de 2008 & 22,0 & 6,1 & 62,6 & 67,8 \\
Abril de 2008 & 21,5 & 6,4 & 4,6 & 55,5 \\
Maio de 2008 & 17,8 & 7,4 & 66,2 \\
\hline
\end{tabular}


e fez-se aplicação do inseticida do grupo piretróide (Decis 25EC) na dose de $200 \mathrm{~mL} / \mathrm{ha}$. Os piquetes foram novamente utilizados, sob pastejo e seguindo o mesmo manejo anterior, somente a partir de meados de fevereiro de 2008.

As características morfogênicas dos perfilhos de capim-braquiária foram avaliadas em locais do pasto onde, inicialmente, as plantas mediam 10, 20, 30 e $40 \mathrm{~cm}$. Em cada piquete, foram marcados 16 perfilhos por meio de anel plástico colorido, sendo quatro perfilhos identificados em cada local do pasto estudado. Foram avaliados dois ciclos decoleta de dados, deno mínimo quatro semanas. Em cada ciclo, novo grupo de perfilhos foi selecionado para avaliação.

Com o auxílio de uma régua graduada, foram efetuadas medições do comprimento das lâminas foliares e do pseudocolmo dos perfilhos marcados, duas vezes por semana. O comprimento das folhas expandidas foi medido desde a ponta da folha até sua lígula. No caso de folhas em expansão, o mesmo procedimento foi adotado, porém considerou-se a lígula da última folha expandida como referencial de mensuração. Para folhas em senescência, o comprimento correspondeu à distância entre o ponto até onde o processo de senescência avançou até a lígula da folha. O tamanho do colmo foi mensurado como a distância desde a superfície do solo até a lígula da folha mais jovem completamente expandida. A partir dessas informações foram calculadas as variáveis: taxa de aparecimento foliar: número de folhas surgidas por perfilho dividido pelo número de dias do período de avaliação; filocrono: inverso da taxa de aparecimento foliar; taxa de alongamento foliar: somatório de todo alongamento da lâmina foliar por perfilho dividido pelo número de dias do período de avaliação; taxa de alongamento de colmo: somatório de todo alongamento de colmo e, ou, pseudocolmo por perfilho dividido pelo número de dias do período de avaliação; duração de vida da folha (DVF): estimada pela equação DVF = número de folha viva por perfilho $\times$ filocrono (Lemaire \& Chapman, 1996); taxa de senescência foliar: variação média e negativa no comprimento da lâmina foliar, resultado da diminuição da porção verde da lâmina foliar, dividido pelo número de dias do período de avaliação; número de folha com desfolhação por perfilho: número médio de folhas por perfilho com remoção parcial ou total da lâmina foliar; número de folhas vivas por perfilho (NFV): número médio de folhas por perfilho completamente expandidas, incluindo as folhas pastejadas; número de folhas mortas por perfilho: número médio de folhas por perfilho com mais de 50 \% da lâmina foliar senescente; comprimento final da lâmina foliar: comprimento médio de todas as folhas presentes no perfilho; comprimento do pseudocolmo: comprimento médio dos pseudocolmos.
As análises dos dados experimentais foram feitas usando o Sistema para Análises Estatísticas - SAEG, versão 8.1 (Universidade Federal de Viçosa, 2003). Para cada característica, foram realizadas análises de variância e de regressão em função da altura das plantas no mesmo pasto, cujos modelos testados foram o linear e o quadrático. O grau de ajustamento dos modelos foi avaliado pelo coeficiente de determinação e pela significância dos coeficientes de regressão, testada pelo teste t corrigido com base nos resíduos da análise de variância.

Inicialmente, todas as análises estatísticas foram realizadas ao nível de até $10 \%$ de probabilidade de ocorrência do erro tipo I, em razão da inerente e natural instabilidade das variáveis morfogênicas e estruturais obtidas com gramíneas forrageiras tropicais em condições de campo e sob pastejo. Contudo, algumas variáveis respostas com efeito significativo para os tratamentos, o apresentaram já ao nível mais baixo de até $5 \%$ de probabilidade.

\section{Resultados e Discussão}

A taxa de aparecimento foliar do capim-braquiária foi influenciada linear e negativamente $(\mathrm{P}<0,10)$ pelas alturas das plantas no mesmo pasto, sendo observada, em média, redução de 15\% (Figura 1a). Este fato pode ser explicado pelo maior tamanho do pseudocolmo dos perfilhos situados nos locais do pasto com maior altura, uma vez que, pseudocolmos de maior comprimento tendem a aumentar o intervalo entre o surgimento de duas folhas consecutivas e, portanto, reduzir a taxa de aparecimento foliar (Skiner \& Nelson, 1995).

Perfilhos presentes nos locais com maior altura apresentaram maior $(\mathrm{P}<0,10)$ filocrono (Figura $1 \mathrm{~b}$ ). Para os perfilhos situados nos locais com $10 \mathrm{~cm}$ e $40 \mathrm{~cm}$ de altura, foram estimados filocronos de 7,9 e 9,3 dias, respectivamente, o que correspondeu a aumento médio de 15\%. Esse mesmo padrão de resposta foi verificado por Sbrissia (2004) em avaliação da $B$. brizantha $\mathrm{cv}$. Marandu sob regimes de lotação contínua com bovinos.

Como o número de folha viva por perfilho é uma característica genotípica estável na ausência de deficiências hídricas e nutricionais (Nabinger \& Pontes, 2001), seria possível inferir que o maior filocrono observado nos perfilhos de locais mais altos aumentaria o tempo para atingir o número máximo de folha e, portanto, para iniciar o processo de senescência. Todavia, o aumento na altura das plantas no mesmo pasto promoveu maior $(\mathrm{P}<0,05)$ taxa de senescência foliar no perfilho de capim-braquiária (Figura 2b). 

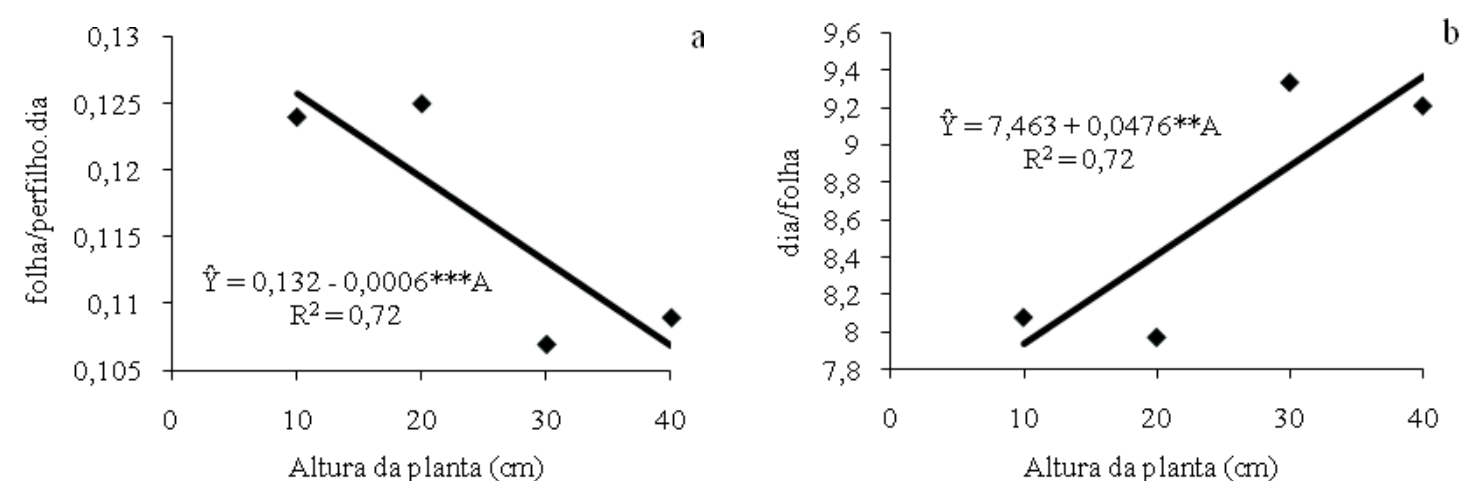

*** Significativo pelo teste $\mathrm{t}(\mathrm{P}<0,10)$; ** Significativo pelo teste $\mathrm{t}(\mathrm{P}<0,05)$.

Figura 1 - Taxa de aparecimento foliar (a) e filocrono (b) de B. decumbens cv. Basilisk em função da altura (A) das plantas no mesmo pasto.
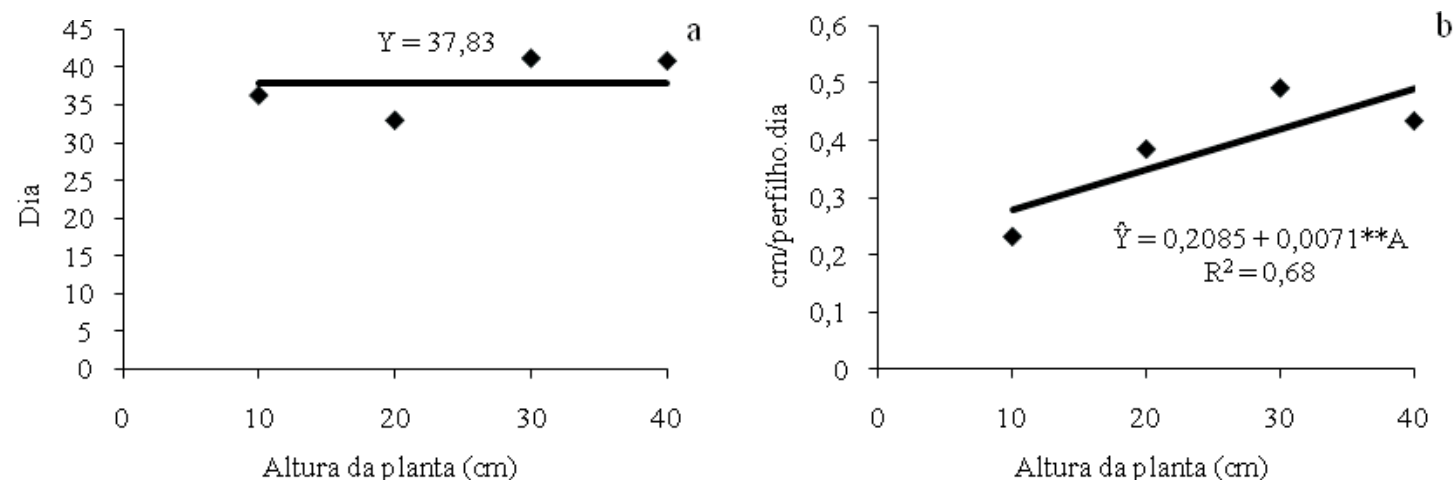

** Significativo pelo teste $\mathrm{t}(\mathrm{P}<0,05)$

Figura 2 - Duração de vida da folha (a) e taxa de senescência foliar (b) de B. decumbens cv. Basilisk em função da altura (A) das plantas no mesmo pasto.

O aumento da taxa de senescência foliar provocado pela maior altura das plantas no mesmo pasto foi de, em média, 43\%. Provavelmente, os perfilhos de locais mais altos do pasto possuíam maior estádio de desenvolvimento e consequentemente, suas lâminas foliares mais velhas atingiram o limite de duração de vida. Além disso, o incremento do sombreamento das lâminas foliares mais velhas e de menor nível de inserção também pode ter ocasionado a elevação na taxa de senescência foliar (Hodgson, 1990). Esses resultados corroboram aqueles obtidos Faria (2009), que quantificou aumento da taxa de senescência foliar na medida em que a altura média do pasto de $B$. decumbens, manejada sob lotação contínua, passou de 10 pra $40 \mathrm{~cm}$.

Devido à maior taxa de senescência foliar nos perfilhos de locais mais altos do pasto, era esperada redução na duração de vida de suas folhas, o que não ocorreu. De fato, a duração média de vida da folha $(37,8)$ não foi influenciada $(\mathrm{P}>0,10)$ pela altura da planta (Figura 2a).
A senescência, muitas vezes, também pode estar associada ao processo de alongamento do pseudocolmo, pois, sob sombreamento, tanto o alongamento do pseudocolmo quanto a senescência de folhas são desencadeados (Lemaire, 2001). De fato, a taxa de alongamento de pseudocolmo aumentou de forma linear com a altura das plantas (Figura 3a), sendo estimados valores médios de $0,11 \mathrm{~cm} /$ dia para os perfilhos nos locais do mesmo pasto com $10 \mathrm{~cm}$ e $0,19 \mathrm{~cm} /$ dia para os perfilhos presentes nos locais com $40 \mathrm{~cm}$ de altura. Resultado semelhante foi obtido por Faria (2009), em avaliação da B. decumbens cv. Basilisk sob lotação contínua e manejada sob as alturas médias de 10, 20, 30 e 40 cm durante 18 meses.

A maior taxa de alongamento de pseudocolmo nos locais do pasto com maior altura pode ser resultado da elevada competição por luz entre os perfilhos nesse local. Nessa condição, a planta prioriza a alocação de carbono no alongamento dos entrenós, para posicionar a nova área foliar nas camadas menos sombreadas do dossel (Lemaire, 2001). 
Por outro lado, não foi observado efeito das variações na altura das plantas de capim-braquiária sobre a taxa de alongamento foliar, que apresentou valor médio de 1,3 cm/perfilho.dia (Figura 3b). Grasselli (2002) também não observou efeito da altura média do relvado sobre a taxa de alongamento foliar da B. decumbens cv. Basilisk manejada em lotação contínua com bovinos. De acordo com Volenec et al. (1983), a taxa de alongamento foliar aumenta sob condições de maior freqüência de pastejo, todavia, os resultados são bastante contraditórios.

Os números de folhas vivas e mortas não foram modificados $(\mathrm{P}>0,10)$ pela altura da planta (Figura 4). Gonçalves (2002) também não constatou efeito da altura média em que os pastos de capim-marandu foram mantidos sobre o número de folhas vivas por perfilho. Segundo Lemaire \& Chapman (1996), o número de folha viva por perfilho, apesar de determinado geneticamente, pode variar com as condições de meio e de manejo da pastagem. Portanto, a ocorrência do número constante de folha viva em perfilhos nos locais avaliados do mesmo pasto pode ser resultado de condições de meio insuficientes para modificar esta variável.

Adicionalmente, o número constante de folha viva por perfilho também pode ter sido decorrente da plasticidade fenotípica do capim-braquiária, que pode ter alterado sua morfogênese por meio de ajustes nas taxas de aparecimento foliar (Figura 1a) e duração de vida das folhas (Figura 2a) de forma a manter relativamente estável o número de folha viva por perfilho.

A inobservância de efeito da altura da planta sobre o número de folhas mortas por perfilho (Figura 4a) se deveu, provavelmente, ao fato de algumas folhas mortas, presentes nos perfilhos de plantas com maior altura, terem se desprendido do pseudocolmo e, portanto, não foram mensuradas durante as avaliações.

Já o aumento na altura das plantas resultou em incremento linear $(\mathrm{P}<0,01)$ no número de folhas com desfolhação (Figura 5), de modo que foi observado aumento de aproximadamente $70 \%$ nessa variável, sendo estimadas 3,36 folhas desfolhadas para os perfilhos
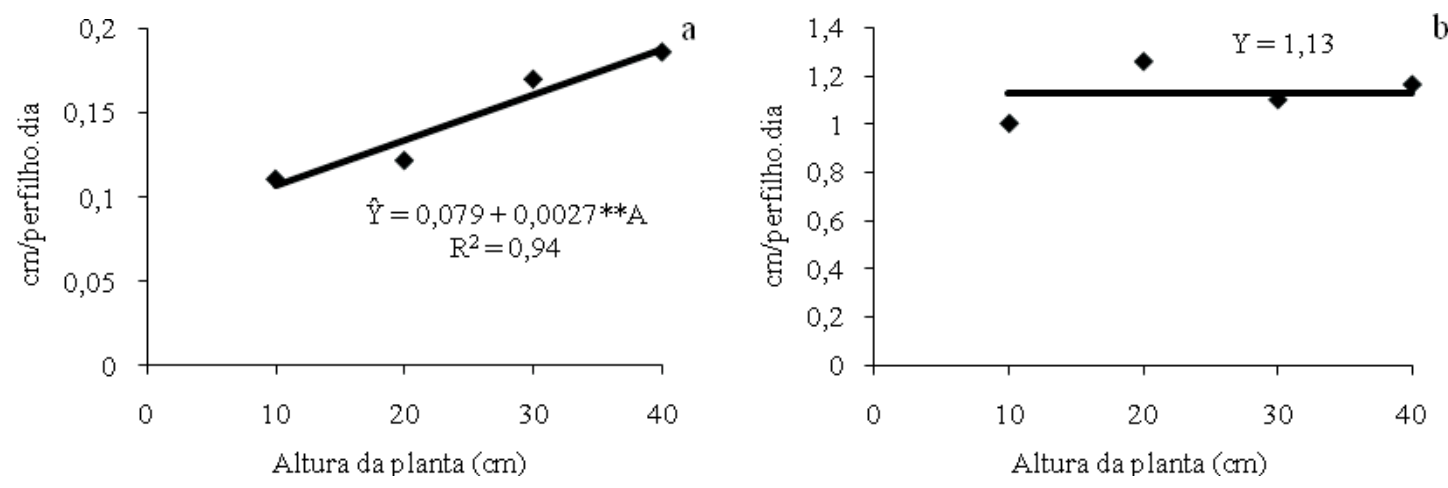

** Significativo pelo teste $\mathrm{t}(\mathrm{P}<0,05)$.

Figura 3 - Taxa de alongamento de pseudocolmos (a) e lâminas foliares (b) de B. decumbens cv. Basilisk em função da altura (A) das plantas no mesmo pasto.
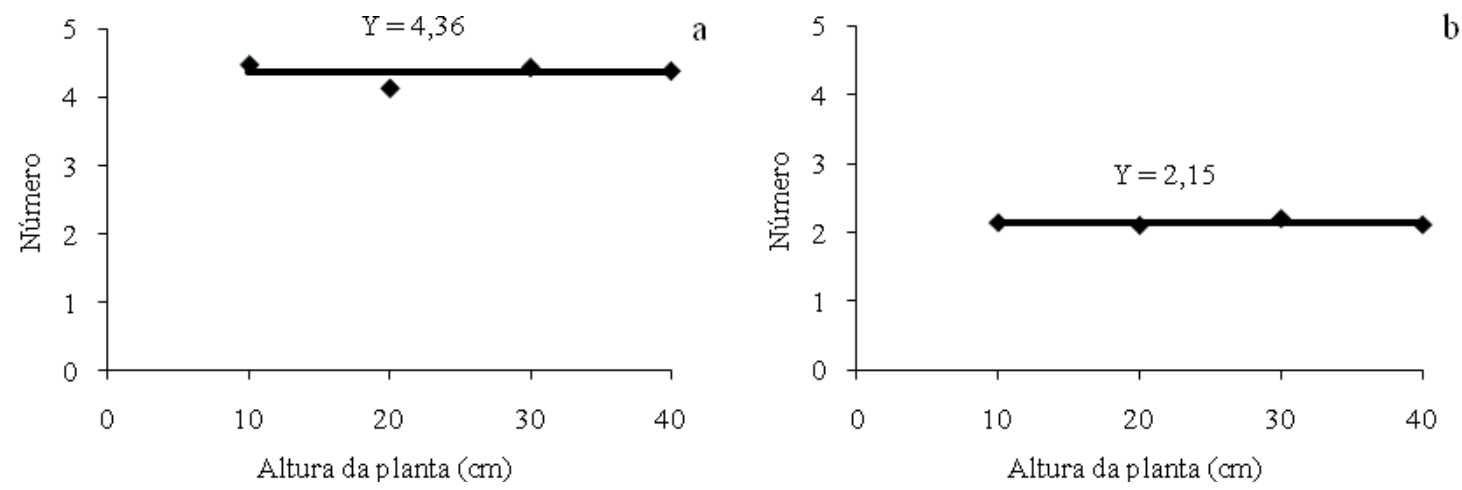

Figura 4 - Número de folhas vivas (a) e mortas (b) em perfilhos de B. decumbens cv. Basilisk em função da altura das plantas no mesmo pasto. 
situados nos locais com $10 \mathrm{~cm}$, e 5,67 folhas desfolhadas nos locais com $40 \mathrm{~cm}$.

Esperava-se redução no número de folhas com desfolhação por perfilho em plantas de maior altura, uma vez que os locais mais altos tendem a serem submetidos às menores freqüências e intensidades de desfolhação, enquanto que os locais mais baixos do mesmo pasto, em geral, são pastejados de forma mais intensa e freqüente pelos bovinos (Carvalho et al., 2001). Entretanto, o reduzido número de folhas com desfolhação em plantas de menor altura pode, possivelmente, ser uma consequência da adaptação morfológica dos perfilhos de capim-braquiária às condições de desfolhação vigentes nesses locais do pasto. De fato, perfilhos de plantas mais baixas, sob desfolhação mais intensa e freqüente, apresentaram menores pseudocolmos e lâminas foliares (Figura 6). Essas adaptações morfológicas, que caracteriza a plasticidade fenotípica do capim-braquiária, provavelmente, diminuíram a probabilidade de ocorrência de desfolhações futuras nas

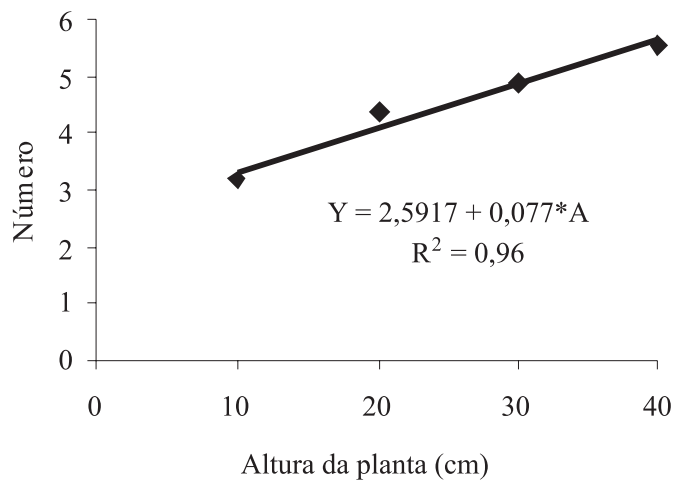

* Significativo pelo teste $\mathrm{t}(\mathrm{P}<0,01)$.

Figura 5 - Número de folha com desfolhação em perfilhos de B. decumbens cv. Basilisk em função da altura (A) das plantas no mesmo pasto.
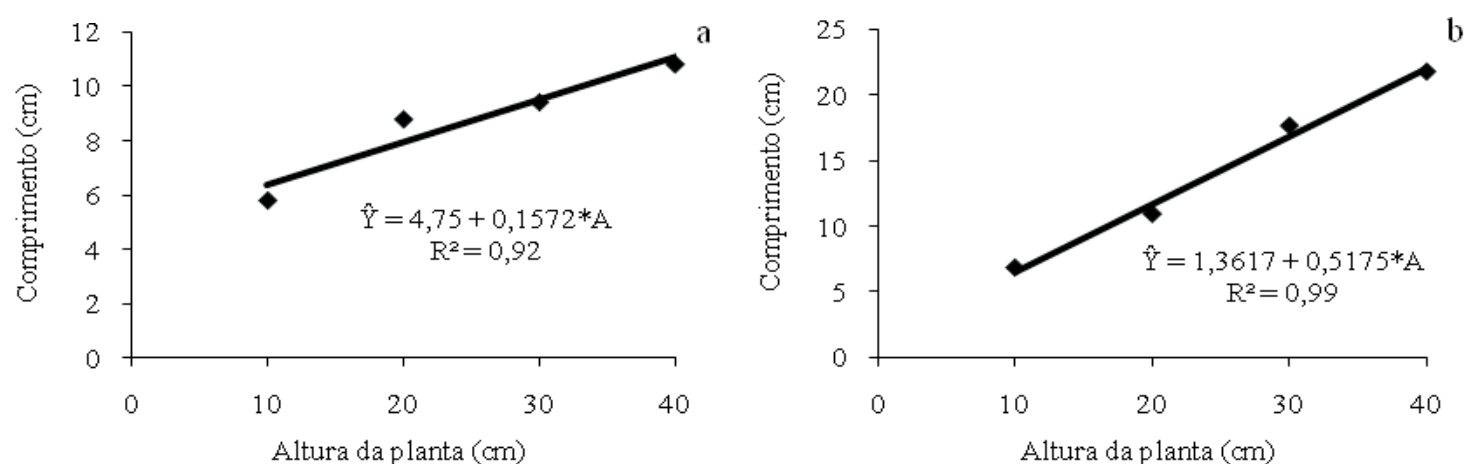

* Significativo pelo teste $\mathrm{t}(\mathrm{P}<0,01)$.

Figura 6 - Comprimento final da lâmina foliar (a) e do pseudocolmo (b) em perfilhos de B. decumbens cv. Basilisk em função da altura (A) das plantas no mesmo pasto.

R. Bras. Zootec., v.40, n.3, p.535-542, 2011 lâminas foliares das plantas com menor altura. Por outro lado, as plantas com maior altura tiveram suas folhas mais susceptíveis à desfolhação, quando os bovinos realizaram o pastejo nesses locais do pasto.

Os argumentos apresentados acima são consistentes com os dados de comprimento final da lâmina foliar e comprimento do pseudocolmo, que responderam linear e positivamente à altura das plantas (Figura 6). O comprimento final da lâmina foliar estimado para as plantas nos locais com $10 \mathrm{~cm} \mathrm{e} 40 \mathrm{~cm}$ foi de $6,37 \mathrm{~cm} \mathrm{e} 11,08 \mathrm{~cm}$, respectivamente, o que correspondeu a aumento de $74 \%$.

O maior comprimento final da lâmina foliar em plantas mais altas pode ser explicado pelo maior tamanho dos perfilhos nesses locais do pasto. Em perfilhos maiores, as folhas mais novas precisam fazer maior percurso no pseudocolmo para se expor. Com isso, a distância percorrida pela folha desde o ponto de conexão com o meristema até a extremidade do pseudocolmo é maior, resultando no seu maior comprimento (Skinner \& Nelson, 1995).

Ademais, é possível inferir que o período de alongamento da lâmina foliar no perfilho presente no local do pasto de maior altura foi superior, uma vez que, nessa condição, o perfilho apresentou maior filocrono (Figura 1b). Isso também pode ter resultado em lâminas foliares de maior comprimento, já que o comprimento da folha é diretamente proporcional à duração do alongamento foliar (Sbrissia \& Da Silva, 2001).

O comprimento do pseudocolmo também respondeu linear e positivamente ao aumento na altura da planta no mesmo pasto (Figura 6b). Foi estimado 6,54 cm de pseudocolmo para as plantas localizadas nos locais com $10 \mathrm{~cm}$, bem como 22,07 cm de pseudocolmo para as plantas presentes nos locais com $40 \mathrm{~cm}$, o que correspondeu ao aumento de $237 \%$. Esses resultados podem estar associados a dois fatores. Primeiramente, os locais com plantas de 
maiores alturas no mesmo pasto geralmente possuem perfilhos com maior estádio de desenvolvimento e, por conseguinte, com maior comprimento do pseudocolmo.

Em adição, plantas de capim-braquiária sob sombreamento, situação comum nos locais com plantas mais altas, também apresentam, como resposta morfológica, o alongamento dos colmos, o que favorece a localização das folhas jovens e mais fotossinteticamente ativa da planta na região superior do dossel, onde a luminosidade é maior.

Os dados apresentados nesse trabalho permitem afirmar que, em um pasto submetido ao mesmo critério de manejo do pastejo, as características morfogênicas e estruturais dos perfilhos são variáveis no plano horizontal da pastagem. Essa variabilidade da morfogênese no pasto é resultado da estrutura horizontal do pasto, que gera microclimas distintos ao longo da área da pastagem. Este microclima, por sua vez, afeta as respostas morfogênicas e a estrutura dos perfilhos individuais. Em adição, os padrões morfogênicos específicos, que ocorrem em cada local do pasto, também contribuem para a existência e manutenção da sua estrutura horizontal.

Dessa forma, a estrutura horizontal do pasto, ao modificar o ambiente próximo dos perfilhos, acaba alterando o padrão de desenvolvimento dos mesmos. Com isso, ocorre um ciclo de variações interdependentes, em que as características morfogênicas de perfilhos individuais afetam a estrutura horizontal do pasto e esta, por conseguinte, desencadeia novas respostas morfogênicas nos perfilhos para manter o equilíbrio homeostático da população de plantas no pasto. Todos esses processos caracterizam a dinâmica, complexa e interdependente natureza dos processos que ocorrem no ecossistema pastagem e que resultam na produção de forragem.

Quando avaliações morfogênicas são feitas em pastos manejados sob lotação contínua, seguindo o critério de manejo baseado na manutenção de mesma altura média do pasto e o uso de taxa de lotação variável; em geral, os locais onde as mensurações são realizadas correspondem àqueles que representam a condição média do pasto. Com isso, fica desconhecido as padrões morfogênicos que operam nas plantas presentes nos locais do pasto com desvios de altura em relação à media. Nesse contexto, as plantas com 10, 20, 30 e $40 \mathrm{~cm}$ de altura apresentaram participação relativa de aproximadamente 16, 55, 28 e $2 \%$, respectivamente, no mesmo pasto de capim-braquiária manejado com altura média de $25 \mathrm{~cm}$ (Santos, 2009). Dessa forma, os dados apresentados nesse trabalho são inéditos e originais, pois permitem entender a diversidade dos processos de desenvolvimento que ocorrem de acordo com a estrutura horizontal do pasto.

\section{Conclusões}

Existe variabilidade espacial da vegetação em pastos de Brachiaria decumbens cv. Basilisk manejados sob lotação contínua com bovinos. A variação natural na altura da planta no mesmo pasto promove mudança nas características morfogênicas e estruturais do capimbraquiária.

\section{Referências}

BRAGA, G.J.; PEDREIRA, C.G.S.; HERLING, V.R. et al. Eficiência de pastejo de capim-marandu submetido a diferentes ofertas de forragem. Pesquisa Agropecuária Brasileira, v.49, n.11, p.1641-1649, 2007.

DA SILVA, S.C.; NASCIMENTO JÚNIOR, D. Avanços na pesquisa com plantas forrageiras tropicais em pastagens: características morfofisiológicas e manejo do pastejo. Revista Brasileira de Zootecnia, v.36, p.121-138, 2007 (supl. especial).

CARVALHO, P.C.F.; RIBEIRO FILHO, H.M.N.; POLI, C.H.E.C. et al. Importância da estrutura da pastagem na ingestão e seleção de dietas pelo animal em pastejo. In: REUNIÃO ANUAL DA SOCIEDADE BRASILEIRA DE ZOOTECNIA, 38., 2001, Piracicaba. Anais... Piracicaba: ESALQ, 2001. p. 883-871.

FARIA, D.J.G. Características morfogênicas e estruturais dos pastos e desempenho de novilhos em capim-braquiária sob diferentes alturas. 2009. 145f. Tese (Doutorado em Zootecnia) - Universidade Federal de Viçosa, Viçosa, MG.

GOMIDE, J.A. Avaliação da pastagem com vacas em lactação: principais delineamentos. In: WORKSHOP DELINEAMENTOS EXPERIMENTAIS COM VACAS EM LACTAÇÃO SOB CONDIÇÃO DE PAStejo, 2006, Juiz de Fora. Anais... Juiz de Fora: EMBRAPA-CNPGL, 2006. (CD-ROM).

GOMIDE, C.A.M.; GOMIDE, J.A.; PACIULLO, D.S.C. Morfogênese como ferramenta para o manejo de pastagens In: REUNIÃO ANUAL DA SOCIEDADE BRASILEIRA DE ZOOTECNIA, 43., João Pessoa, 2006. Anais... João Pessoa: SBZ, 2006. p.554-579.

GONÇALVES, A.C. Características morfogênicas e padrões de desfolhação em pastos de capim-Marandu submetidos a regimes de lotação contínua. 2002. Dissertação (Mestrado em Agronomia - Ciência Animal e Pastagens) - Escola Superior de Agricultura "Luiz de Queiroz" - Piracicaba.

GRASSELLI, L.C.P. Características estruturais e morfogênicas e acúmulo de forragem em relvado de Brachiaria decumbens cv. Basilisk sob pastejo, a diferentes alturas. 2002. 50f. Dissertação (Mestrado em Zootecnia) - Universidade Federal de Viçosa, Viçosa, MG.

HODGSON, J. Grazing management - science into practice. Essex: Longman Scientific \& Technical, 1990. 203p.

LEMAIRE, G. Ecophisiology of grasslands: dinamic aspects of forage plant populations in grazed swards. In: INTERNATIONAL GRASSLAND CONGRESS, 19., 2001, São Pedro, 2001. Proceedings... São Pedro: FEALQ, 2001. p.29-37.

LEMAIRE, G.; CHAPMAN, D. Tissue flows in grazed plant communities. In: HODGSON, J.; ILliUS, A.W. (Eds.) The ecology and management of grazing systems. Wallingford: CAB International, 1996. p.3-36.

NABINGER, C.; PONTES, L.S. Morfogênese de plantas forrageiras e estrutura do pasto. In: REUNIÃO ANUAL DA SOCIEDADE BRASILEIRA DE ZOOTECNIA, 38., 2001, Piracicaba. Anais... Piracicaba: ESALQ, 2001. p.755-771. 
SANTOS, M.E.R. Variabilidade espacial e dinâmica do acúmulo de forragem em pastos de capim-braquiária sob lotação contínua. 2009. 144f. Tese (Doutorado em Zootecnia), Universidade Federal de Viçosa, Viçosa, MG.

SBRISSIA, A.F. Morfogênese, dinâmica do perfilhamento e do acúmulo de forragem em pastos de capim-Marandu sob lotação contínua. 2004. Tese (Doutorado em Agronomia - Ciência Animal e Pastagens) - Escola Superior de Agricultura "Luiz de Queiroz", Piracicaba.

SBRISSIA, A.F., Da SILVA, S.C. O ecossistema de pastagens e a produção animal In: REUNIÃO ANUAL DA SOCIDADE BRASILEIRA DE ZOOTECNIA, 38., 2001, Piracicaba. Anais... Piracicaba: SBZ, 2001. p.731-754.
SCHWARTZ, F.; ROCHA, M.G.; VÉRAS, M. et al. Manejo de milheto (Pennisetum americanum Leeke) sob pastejo de ovinos. Revista Brasileira Agrociência, v.9, n.2, p.151-155, 2003.

SKINNER, R.H.; NELSON, C.J. Elongation of the grass leaf and its relationship phillochron. Crop Science, v.35, n.1, p.4-10, 1995.

UNIVERSIDADE FEDERAL DE VIÇOSA - UFV. SAEG - Sistema de análises estatísticas e genéticas. Versão 8.1. Viçosa, MG: 2003. 57p. (Apostila).

VOLENEC, J.J.; NELSON, C.J. Responses of tall fescue leaf meristems to $\mathrm{N}$ fertilization and harvest frequency. Crop Science, v.23, p.720-724, 1983 